\title{
Measurement and Convergence Analysis of Total Factor Energy Efficiency in Yangtze River Economic Belt
}

\author{
Chen $\mathrm{Xu}$ \\ Economics and Management School, Wuhan University, Wuhan 430072, China
}

Corresponding Author Email: chenxuecon@whu.edu.cn

https://doi.org/10.18280/ijsdp.150503

Received: 28 January 2020

Accepted: 6 April 2020

\section{Keywords:}

Yangtze river economic belt (YREB), total factor energy efficiency (TFEE), directional distance function $(D D F)$ model, beta convergence model (BCM)

\begin{abstract}
This paper sets up an evaluation index system for total factor energy efficiency (TFEE), and measures the 2000-2017 TFEEs of the 11 provinces (municipalities) in the Yangtze River Economic Belt (YREB). After analysing the regional differences in YREB TFEE, the beta convergence model (BCM) was introduced to empirically explore the convergence of the YREB TFEE. The results show that: The YREB provinces (municipalities) differed greatly in TFEE. Among them, Shanghai, Zhejiang and Yunnan achieved the optimal TFEEs in the sample period; Jiangsu, Anhui, Hubei, Hunan, Chongqing, and Sichuan realized relatively good TFEEs; Jiangxi and Guizhou did not output desirable TFEEs, leaving ample room for improvement. There were significant TFEE differences between the upstream, midstream, and downstream of the YREB. The three regions can be ranked as downstream, midstream, and upstream in descending order of the TFEE. The YREB TFEE exhibited significant absolute beta convergence. The midstream TFEE had the fastest absolute convergence speed, followed in turn by the upstream TFEE and the downstream TFEE. The addition of control variables improved the conditional convergence speeds of YREB TFEEs. Except energy structure (ECS), the control variables, including economic level (PGDP), foreign trade (TRD), environmental regulation (ERS), and urbanization rate (URB), exerted major impacts on the YREB TFEE. The impacts varied from region to region. The research results provide a good reference for energy saving and emission reduction in the YREB.
\end{abstract}

\section{INTRODUCTION}

The Yangtze River Economic Belt (YREB) covers 11 provinces (municipalities) in China, namely, Shanghai, Jiangsu, Zhejiang, Anhui, Jiangxi, Hubei, Hunan, Chongqing, Sichuan, Yunnan, and Guizhou. Taking up 21\% of China's territorial area, the YREB is home to $40 \%$ of the Chinese population.

With a vast hinterland and development space, the YREB has developed into one of the most dynamic economic belts in China, thanks to strategic supports of the country. Over the years, the YREB has successfully forged industrial clusters in the fields of steel, petrochemicals, automobiles, and electronics. In 2019, the GDP of the YREB accounted for $46 \%$ of the national total.

Despite the rapid development, the YREB, whether upstream, midstream, or downstream, is faced with an increasingly severe energy shortage. From 2000 to 2017, the resource consumption in the YREB swelled by 3.12 times from $550,886,600$ to $1,716,790,000$ tons of standard coal. Currently, the self-sufficiency rate of primary energy is merely $52 \%$ in the YREB. The energy gap of the YREB will further widen, as the energy demand continuous to grow.

In the meantime, the pollutant emissions of the YREB have been rising with the continuous growth of energy consumption. For instance, the YREB emitted $34 \%$ of China's total $\mathrm{SO}_{2}$ emissions in 2016. Against this background, the Chinese government has repeatedly stressed that the YREB should optimize its energy structure, strictly limit energy consumption, and pursue green eco-friendly development, turning itself into a belt of green energy industry. Under the joint constraints of energy and environment, the YREB must further improve energy efficiency to curb excessive energy consumption and realize green development.

Energy shortage is a bottleneck for the economic growth and social progress around the world. As a result, energy efficiency has become a hot topic in the academia. The existing studies on energy efficiency mainly focus on the five aspects below:

(1) Definition of energy efficiency

There are two kinds of definitions of energy efficiency: single-factor definition and total-factor definition. The former defines energy efficiency by a single factor, such as intensity, eco-efficiency, productivity, and technology efficiency [1, 2]; the latter defines energy efficiency by total factor, including capital, labor, energy, etc. [3].

(2) Evaluation index system of energy efficiency

Initially, only desirable output was included in the evaluation index system $[4,5]$. Later, the undesirable output was added to the system to make the evaluation more reasonable. For example, Seiford and Zhu [6] and Färe et al. [7] have incorporated undesirable output into the evaluation index system of energy efficiency.

(3) Evaluation method of energy efficiency

At present, energy efficiency is generally evaluated by data envelopment analysis (DEA) or stochastic frontier analysis 
(SFA). For instance, Boyd and Pang [8] and Hu and Kao [9] measured energy efficiency by the DEA, while Miao and Jin [10] and Lin and Long [11] evaluated energy efficiency by the SFA.

\section{(4) Spatial scale of energy efficiency}

In terms of spatial scale, relevant scholars have evaluated the energy efficiency of a single country [12], and compared that between different regions [13] or between different countries [14].

(5) Influencing factors of energy efficiency

The previous studies have shown that energy efficiency is greatly affected by various factors, including but not limited to industrial structure [15], technical progress [16], energy audit [17], national industrial policy [18], and financial development [19].

To sum up, fruitful results have been achieved on energy efficiency, especially in terms of definition, evaluation index system, evaluation method, spatial scale, and influencing factors. However, there is no report on the convergence of energy efficiency, not to mention the convergence of the total factor energy efficiency (TFEE) in the YREB.

To make up for the gap, this paper measures the YREB TFEE with the directional distance function (DDF) model, and discloses its evolution features and regional differences. On this basis, the convergence model was adopted to explore the convergence of the YREB TFEE. The research results provide a good reference for energy saving and emission reduction in the YREB.

\section{METHODOLOGY}

\subsection{DDF}

In this paper, the YREB TFEE is measured by the DEA, a flexible tool of nonparametric analysis. Proposed by Charnes et al. [20], the DEA is widely adopted in efficiency evaluation, because it can handle problems with multiple inputs and outputs, without needing the production function. The working principles of the DEA are as follows:

Suppose a production system involves multiple decisionmaking units (DMUs). During the production, each DMU needs to generate the output based on the production factors inputted to the system. The DMUs differ in the input-output ratio. If a DMU falls on the optimal frontier, then it is an optimal DMU with the efficiency of 1; otherwise, the DMU is invalid with an efficiency smaller than 1 . The efficiency measured by the DEA is a relative value, rather than an absolute value.

Since its proposal, the DEA has been constantly updated. The early versions of DEAs, namely, Chames-Cooper-Rhodes (CCR) model and Banker-Chames-Cooper (BCC) model, can work effectively on evaluation index systems of multiple inputs and multiple outputs. However, these models can only process desirable output indices. If an output index is undesirable, it must be converted into a desirable index before being imported to these models.

To solve the problem, Chambers et al. [21] improved the above models into the DDF model. Compared with traditional models, the DDF model can deal with problems with undesirable output, and improve the invalid DMUs into effective ones by reducing inputs or increasing the outputs. The workflow of the DDF model is explained as follows:
Let there be a production system with n DMUs, each of which can produce $d$ units of desirable output and $u$ units of undesirable output from $\mathrm{m}$ units of input. For simplicity, the DMU to be evaluated is denoted as $D M U_{0}=\left(x_{0}, y_{0}^{g}, y_{0}^{b}\right)$, while the input, desirable output, and undesirable output are denoted as vectors $X=\left(x_{1}, x_{2}, \ldots, x_{n}\right) \in R_{+}^{m \times n}, Y=$ $\left(y_{1}, y_{2} \ldots, y_{n}\right) \in R_{+}^{d \times n}$, and $b=\left(b_{1}, b_{2} \ldots, b_{n}\right) \in R_{+}^{u \times n}$, respectively. Then, the production possibility set (PPS) of the production system can be expressed as: $P^{t}(x)=$ $\{(x, y): x$ can lead to $y\}$. On this basis, the DDF model can be expressed as:

$$
\begin{aligned}
& \vec{D}_{0}\left(x, y, b ; g_{y},-g_{b}\right)= \\
& \sup _{\theta}\left(\theta:\left(y+\theta_{y_{y}}, b-g_{b}\right) \in P(x, y, b)\right\}
\end{aligned}
$$

Formula (1) reflects two properties of the DDF model: the model outputs include a desirable output $y$ and an undesirable output $b$, which are closely correlated with each other; the undesirable output is weakly disposable, that is, any reduction of the undesirable output will cause the proportional decline of the desirable output. Based on these properties, the optimal solution of the DDF model can be obtained by:

$$
\begin{gathered}
\vec{D}_{0}^{t}\left(x^{t k}, y^{t k}, b^{t k} ; g_{y}^{t k},-g_{b}^{t k}\right)=\max \theta \\
\text { s.t. } \$ \sum_{j=1}^{n} \lambda_{j} y_{r j}^{t} \geq(1+\theta) y_{r k}^{t}, r=1,2, \ldots, d \\
\sum_{j=1}^{n} \lambda_{j} b_{l j}^{t}=(1-\theta) b_{l k}^{t}, l=1,2, \ldots, u \\
\sum_{j=1}^{n} \lambda_{j} x_{i j}^{t} \leq(1-\theta) x_{i k}^{t}, i=1,2, \ldots, m \\
\lambda_{j} \geq 0, j=1,2, \ldots, n
\end{gathered}
$$

where, $x^{t k}, y^{t k}, b^{t k}, g_{y}^{t k}$, and $-g_{b}^{t k}$ are the input, desirable output, undesirable output, increment of desirable output, and decrement of undesirable output, respectively; $\theta$ s the distance between the desirable output $y^{t k}$ and the undesirable output $b^{\text {tk }}$.

In terms of efficiency, the $\theta$ value reflects the proportional relationship between the increment of desirable output and decrement of undesirable output. The greater the $\theta$ value, the longer the distance between desirable and undesirable outputs, and the less efficient the DMU. In this case, there is ample room to improve the increment of desirable output and decrement of undesirable output. The smaller the $\theta$ value, the more efficient the DMU, and the smaller. In this case, there is little room to improve the said factors. Only if $\theta=0$, the DMU falls on the optimal frontier of the production system and has an efficiency of 1 , leaving no room to improve the said factors.

\subsection{Beta convergence model (BCM)}

This paper attempts to answer the following question: whether the TFEEs of YREB provinces (municipalities) converge with the elapse of time? This question needs to be solved by a scientific convergence method.

The convergence method was first used to judge whether the income gap of residents in different countries or regional will converge. The premise of this method is the law of diminishing marginal returns, which means the income growth rate varies with the economic levels. In general, the income 
growth rate is relatively slow in developed areas, and relatively fast in underdeveloped areas. As time goes by, the income gap between developed and underdeveloped areas will gradually narrow.

The convergence method has attracted great interest from the academia. Apart from resident income, this method has been extensively applied in such field as economic growth, foreign trade, and ecological environment. Currently, the most popular convergence method is the BCM, which can be further divided into absolute $\mathrm{BCM}$ and conditional $\mathrm{BCM}$.

Absolute $\mathrm{BCM}$ is relatively simple. Without considering external factors, the TFEEs of YREB provinces (municipalities) will converge. According to the convergence model designed by Barro and Sala-i-Martin [22], the absolute BCM for the YREB TFEE can be defined as:

$$
\operatorname{gTFEE}_{i, t}=\alpha_{i}+\beta \operatorname{Ln}\left(\operatorname{TFEE}_{i, t-1}\right)+\mu_{i, t}
$$

where, $g T F E E_{i, t}$ is the TFEE growth rate of province (municipality) $i$ in year $t\left(g T F E E_{i, t}=\Delta \operatorname{Ln}\left(T F E E_{i, t}\right)=\right.$ $\left.\operatorname{Ln}\left(T F E E_{i, t}\right)-\operatorname{Ln}\left(T F E E_{i, t-1}\right)\right) ; \operatorname{Ln}\left(T F E E_{i, t-1}\right)$ is the natural logarithm of TFEE of province (municipality) $\mathrm{i}$ in year $t-1 ; \mu_{i, t}$ is an random error. If the coefficient beta of $\operatorname{Ln}\left(T F E E_{i, t-1}\right)$ is negative, then the TFEE growth has an obvious trend of convergence.

Absolute BCM focuses purely on the convergence of the provincial (municipal) TFEEs in the YREB. In the real world, the TFEE is affected by multiple factors. Considering these factors, conditional BCM can solve the TFEE convergence more realistically.

Drawing on the results of Brookes [23], Murtishaw and Chipper [24], Herrerias et al. (2013) [25] and Gollop and Roberts [26], this paper summarizes the factors that affect the TFEE and cause it to converge into five control variables: economic level (PGDP), foreign trade (TRD), energy structure (ECS), environmental regulation (ERS), and urbanization rate (URB). On this basis, the conditional BCM for the YREB TFEE can be established as:

$$
\begin{aligned}
& \operatorname{gTFEE}_{i, t}=\alpha_{i}+\beta_{1} \operatorname{Ln}\left(\operatorname{TFEE}_{i, t-1}\right)+ \\
& \beta_{2} \operatorname{PGDP}_{i, t}+\beta_{3} \operatorname{TRD}_{i, t}+\beta_{4} E C S_{i, t} \\
& +\beta_{5} E S_{i, t}+\beta_{6} U R B_{i, t}+\mu_{i, t}
\end{aligned}
$$

where, $g T F E E_{i, t}$ and $\operatorname{Ln}\left(T F E E_{i, t-1}\right)$ are the same as in formula (3); PGDP is the economic level; TRD is foreign trade; ECS is energy structure; ERS is environmental regulation; $\mathrm{URB}$ is urbanization rate.

Specifically, PGDP, TRD, ECS, ERS, and URB are respectively characterized by the natural logarithm of percapita gross domestic product (GDP), the total volume of import and export as a proportion of GDP, the coal consumption as a proportion of total energy consumption, the investment on industrial pollution control as a proportion of gross industrial output, and the urban permanent population as a proportion of the total population in each province (municipality) of the YREB.

\subsection{Evaluation index system}

Inspired by Hu and Wang [27], the TFEE was defined as the set of possible outputs that can be achieved based on various inputs, including labor, capital, and energy. If the inputs are fixed, the TFEE reflects the maximum desirable output or the minimum undesirable output; if the outputs are fixed, the TFEE reflects the minimum inputs. The TFEE value falls within $[0,1]$. The greater the input-output ratio, the higher the TFEE; the smaller the ratio, the lower the TFEE.

The evaluation index system is a necessary condition for TFEE evaluation. Referring to $\mathrm{Li}$ and $\mathrm{Hu}$ [28] and Simsek [29], this paper sets up an evaluation index system for the YREB TFEE, which is scientific, complete, and operable. As shown in Table 1, the proposed evaluation index system consists of three input indices, one desirable output index, and two undesirable output indices.

Table 1. Evaluation index system for the YREB TFEE

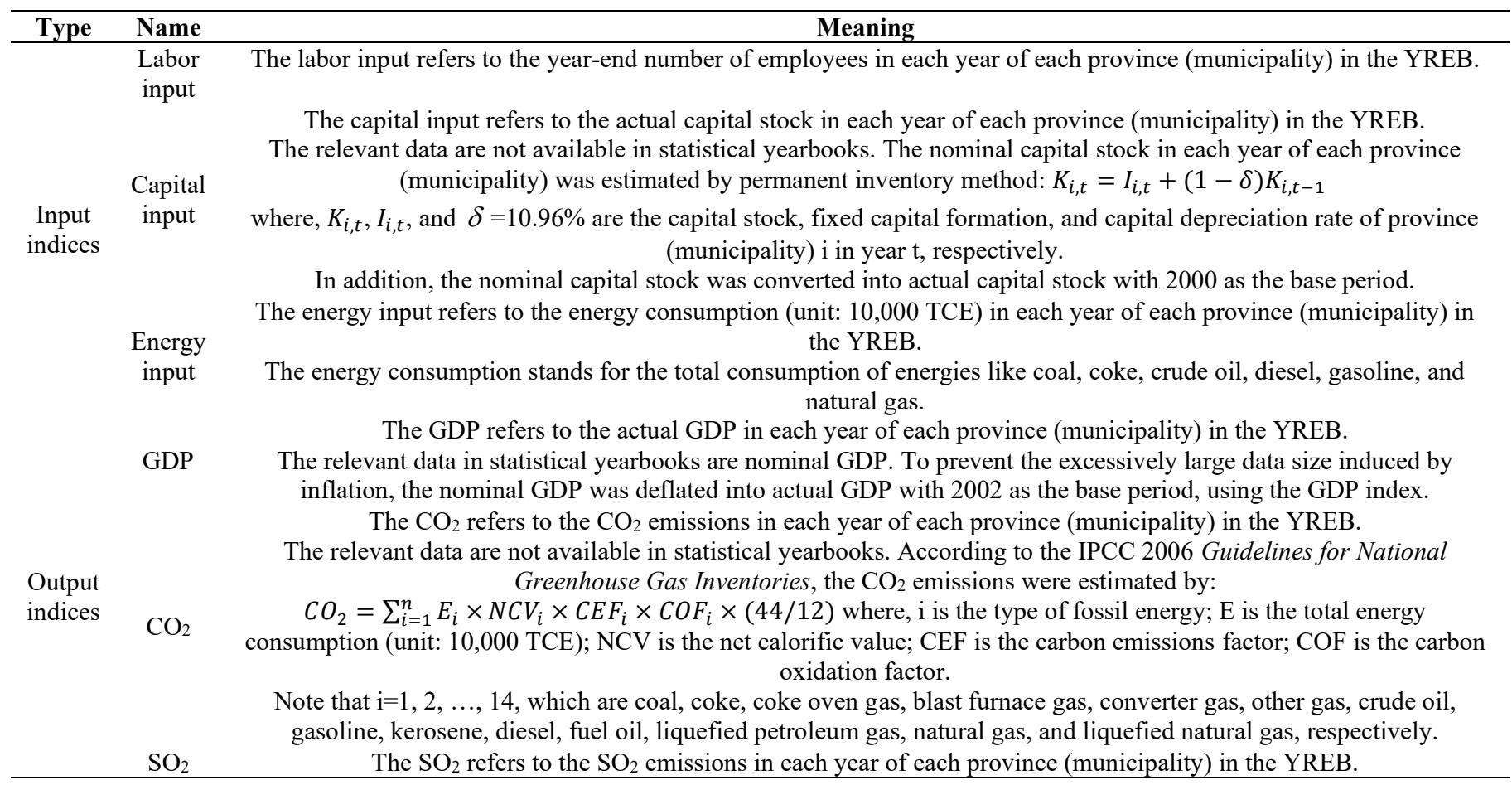


The three input indices are labor input, capital input, and energy input:

\section{(1) Labor input}

Labor force is an essential input for regional economy. Labor force shortage hinders effective use of energy, and hampers the normal operations of enterprises. Thus, labor input is indispensable to our evaluation index system.

(2) Capital input

Capital is another essential input for economic growth. Without capital support, it is impossible for enterprises to purchase equipment or pay the wages of workers. As a result, capital is also a necessary input in our evaluation index system.

(3) Energy input

Energy is the core input of the evaluation index system for the TFEE. To promote economic growth, energy must be combined with other factors like capital and labor.

The desirable output refers to the good output of energy utilization. GDP reflects the outcome of the production activities of all units in a region. It is the best indicator of regional economy. Therefore, GDP was selected as the desirable output index.

The undesirable outputs refer to the bad outputs of energy utilization, that is, the pollutants released from energy consumption. Here, carbon dioxide $\left(\mathrm{CO}_{2}\right)$ and sulfur dioxide $\left(\mathrm{SO}_{2}\right)$ are taken as the undesirable output indices. The two gases are closely related to energy utilization.

\subsection{Data sources}

Considering data completeness and availability, this paper adopts the panel data of the 11 provinces (municipalities) in the YREB in 2000-2017. The data on GDP, per-capita GDP, GDP index, year-end number of employees, energy consumption, coal consumption, fixed asset formation, $\mathrm{SO}_{2}$, total volume of import and export, investment on industrial pollution control, and gross industrial output were extracted from China Statistical Yearbooks, China Energy Statistical Yearbooks, China Statistical Yearbooks on Environment, China Industry Statistical Yearbooks, the statistical yearbooks published by the YREB provinces (municipalities), and the website of the National Bureau of Statistics of China.

\section{RESULTS}

\subsection{Evaluation of the YREB TFEE}

Th established evaluation index system for the TFEE and input and output data were imported into maxDEA to measure the TFEEs of the 11 YREB provinces (municipalities) in 20002017. The results are recorded in Table 2.

As shown in Table 2, there are significant differences between the YREB provinces (municipalities) in TFEE. Based on the TFEE values, the 11 provinces (municipalities) were divided into three levels.

The first level contains two provinces (Zhejiang and Yunnan) and one municipality (Shanghai), whose TFEEs remained at 1 throughout the sample period. The TFEEs of the three provinces (municipalities) were optimized for the following reasons: Shanghai and Zhejiang are located in the economically developed eastern region of China. The enterprises have advanced production technology, and can make effective use of energy. Besides, the two regions have attached importance to the green transform of economy, and continuously optimized the industrial structure, thereby enhancing the ability of enterprises to save energy and reduce emissions. The high TFEEs of Yunnan come from the special industrial structure: the agriculture is highly developed, and the industrial landscape is dominated by light industry. That is why Yunnan consumes relatively few energies and emit a limited amount of pollutants.

The second level contains six provinces whose TFEEs fell between 0.9 and 1, including Jiangsu, Anhui, Hubei, Hunan, Chongqing, and Sichuan. In some years, the TFEEs of these provinces were not optimal, leaving a room for improvement. The possible reasons are as follows: Despite developed economy and advanced production technology, Jiangsu has an industrial system dominated by heavy industry, resulting in high energy consumption and heavy pollutant emissions. In recent years, Anhui, Hubei, Hunan, Chongqing, and Sichuan have achieved relatively fast economic growth in China. Albeit creating economic wealth, the booming economy pushes up the energy demand. Unfortunately, these provinces have not improved the production technology of enterprises, failing to effectively promote the ability to save energy and reduce emissions.

Table 2. The TFEEs of YREB provinces (municipalities) in 2000-2017

\begin{tabular}{cccccccccccc}
\hline Year & Shanghai & Jiangsu & Zhejiang & Anhui & Jiangxi & Hubei & Hunan & Chongqing & Sichuan & Guizhou & Yunnan \\
\hline 2000 & 1.0000 & 1.0000 & 1.0000 & 0.7531 & 0.9209 & 0.8356 & 1.0000 & 0.7067 & 0.7370 & 0.4235 & 1.0000 \\
2001 & 1.0000 & 1.0000 & 1.0000 & 1.0000 & 0.8786 & 0.9347 & 1.0000 & 0.7919 & 0.8497 & 0.4255 & 1.0000 \\
2002 & 1.0000 & 1.0000 & 1.0000 & 1.0000 & 0.7475 & 0.9733 & 1.0000 & 0.9147 & 0.8891 & 0.4203 & 1.0000 \\
2003 & 1.0000 & 1.0000 & 1.0000 & 1.0000 & 0.7322 & 0.9738 & 1.0000 & 0.9163 & 0.8733 & 0.4324 & 1.0000 \\
2004 & 1.0000 & 1.0000 & 1.0000 & 1.0000 & 0.8009 & 0.9745 & 1.0000 & 0.9096 & 0.8767 & 0.4345 & 1.0000 \\
2005 & 1.0000 & 0.9876 & 1.0000 & 1.0000 & 0.8552 & 1.0000 & 0.9257 & 0.9236 & 1.0000 & 0.4506 & 1.0000 \\
2006 & 1.0000 & 0.9867 & 1.0000 & 1.0000 & 0.8490 & 0.9981 & 0.9028 & 0.9199 & 1.0000 & 0.4457 & 1.0000 \\
2007 & 1.0000 & 0.9859 & 1.0000 & 1.0000 & 0.8417 & 1.0000 & 0.9157 & 0.9303 & 1.0000 & 0.4505 & 1.0000 \\
2008 & 1.0000 & 0.9914 & 1.0000 & 1.0000 & 0.8503 & 1.0000 & 0.9061 & 0.9377 & 1.0000 & 0.4446 & 1.0000 \\
2009 & 1.0000 & 1.0000 & 1.0000 & 1.0000 & 0.8381 & 1.0000 & 0.9257 & 0.9519 & 1.0000 & 0.4399 & 1.0000 \\
2010 & 1.0000 & 1.0000 & 1.0000 & 1.0000 & 0.8524 & 1.0000 & 0.9303 & 0.9874 & 1.0000 & 0.5182 & 1.0000 \\
2011 & 1.0000 & 1.0000 & 1.0000 & 1.0000 & 0.8232 & 1.0000 & 0.9023 & 0.9975 & 1.0000 & 0.5285 & 1.0000 \\
2012 & 1.0000 & 1.0000 & 1.0000 & 1.0000 & 0.8188 & 1.0000 & 0.9046 & 1.0000 & 1.0000 & 0.5238 & 1.0000 \\
2013 & 1.0000 & 1.0000 & 1.0000 & 1.0000 & 0.7997 & 1.0000 & 0.9250 & 1.0000 & 1.0000 & 0.5111 & 1.0000 \\
2014 & 1.0000 & 1.0000 & 1.0000 & 1.0000 & 0.7640 & 1.0000 & 0.9300 & 1.0000 & 1.0000 & 0.4945 & 1.0000 \\
2015 & 1.0000 & 1.0000 & 1.0000 & 1.0000 & 0.7610 & 1.0000 & 0.9123 & 1.0000 & 1.0000 & 0.4763 & 1.0000 \\
2016 & 1.0000 & 1.0000 & 1.0000 & 1.0000 & 0.7668 & 1.0000 & 0.9075 & 1.0000 & 1.0000 & 0.4646 & 1.0000 \\
2017 & 1.0000 & 1.0000 & 1.0000 & 1.0000 & 0.7680 & 1.0000 & 0.9237 & 1.0000 & 1.0000 & 0.4611 & 1.0000 \\
Mean & 1.0000 & 0.9973 & 1.0000 & 0.9863 & 0.8149 & 0.9828 & 0.9395 & 0.9382 & 0.9570 & 0.4636 & 1.0000 \\
\hline
\end{tabular}


The third level contains several provinces and one municipality whose TFEEs were below 0.9. Among them, the mean TFEEs of Jiangxi and Guizhou were only 0.8149 and 0.4636 , respectively. The TFEEs of the two provinces were undesirable, owing to the backward economy and the neglection of improving production technology. What is worse, both provinces are major coal producers. Coal accounts for a large proportion of the energy structure. Therefore, Jiangxi and Guizhou emit more pollutants than the other regions in the YREB.

In summary, the YREB provinces (municipalities) differed greatly in TFEE. During the sample period, only Shanghai, Zhejiang and Yunnan optimized their TFEEs; the other provinces (municipalities) had room for improving the TFEE. In particular, Jiangxi and Guizhou faced ample room for TFEE improvement. This means the YREB provinces (municipalities) should take different policies on energy saving and emission reduction, in order to build the YREB into a pioneer and role model of ecological civilization.

The regional differences of the YREB TFEE were further analyzed by dividing the YREB into three regions: upstream, midstream, and downstream. Figure 1 shows the trends of overall, downstream, midstream, and upstream TFEEs in the YREB in 2000-2017. It can be seen that the downstream TFEE basically remained at 1 in the sample period, and only fell slightly below 1 in 2005, 2006 and 2007. The midstream TFEE surged up in 2000-2001, and remained stable in the following years. The upstream TFEE slowly rose throughout the sample period.

The three regions had significant differences in the TFEE. Among them, the downstream TFEE averaged at 0.9991, much higher than the overall average of 0.9163 ; the midstream TFEE averaged at 0.9309 , close to the overall average; the upstream TFEE was merely 0.8397, far below the overall average. The three regions can be ranked as downstream, midstream, and upstream in descending order of the TFEE. Therefore, midstream and upstream should be the focus of energy saving and emission reduction in the YREB.

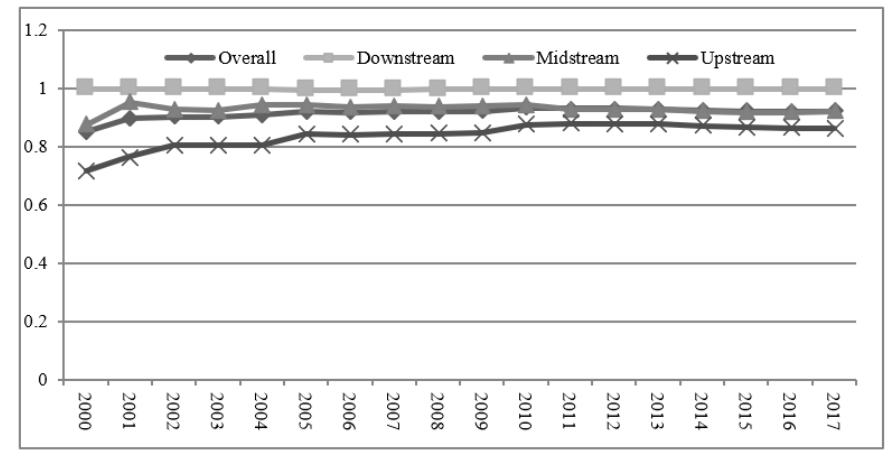

Figure 1. Overall, downstream, midstream, and upstream TFEEs in the YREB

\subsection{Convergence analysis}

\subsubsection{Results analysis of absolute BCM}

The absolute BCM (3) for the YREB TFEE was regressed on Stata 12. The regression results are displayed in Table 3. To choose between fixed-effects model and random-effects model, the F-statistic was used to test the panel data on the overall, downstream, midstream, and upstream of the YREB.

As shown in Table 3, the F-statistics of the overall, midstream, and upstream of the YREB were respectively
$17.96,4.65$ and 16.86, and all passed the significance test at $1 \%$. Thus, individual fixed effects exist in the panel data on the overall, midstream, and upstream of the YREB. It is better to choose fixed-effects model for these data. By contrast, the F-statistics of the downstream was merely 0.63 , and did not pass the significance test. This means individual fixed effects do not exist in the panel data on the downstream. Random effects model is more suitable for the data.

Table 3. Regression results of absolute BCM

\begin{tabular}{|c|c|c|c|c|}
\hline Variable & Overall & Downstream & Midstream & 1 Upstream \\
\hline $\operatorname{Ln}(T F E E t-1)$ & $\begin{array}{c}-0.5446^{* * *} \\
(-12.76)\end{array}$ & $\begin{array}{c}-0.2335^{* * *} \\
(-2.54)\end{array}$ & $\begin{array}{c}-0.7432^{* * *} \\
(-9.66)\end{array}$ & $\begin{array}{c}-0.4101^{* * *} \\
(-6.69)\end{array}$ \\
\hline $\operatorname{Adj} R^{2}$ & 0.4818 & 0.1163 & 0.5968 & 0.4153 \\
\hline F-statistic & $17.96^{* * *}$ & 0.63 & $4.65^{* * *}$ & $16.86^{* * *}$ \\
\hline$o b s$ & 198 & 54 & 72 & 72 \\
\hline
\end{tabular}
levels of $10 \%, 5 \%$ and $1 \%$, respectively

It can also be seen from Table 3 that the $\operatorname{Ln}(T F E E t-1)$ coefficients of the overall, downstream, midstream, and upstream of the YREB were respectively $-0.5446,-0.2335$, 0.7432 , and -0.4101 , and all passed the significance test at $1 \%$. This fully demonstrates that the YREB TFEE exhibited significant absolute beta convergence, and that the TFEE growth rate of a province (municipality) is negatively correlated with the initial TFEE of that province (municipality). With the elapse of time, the TFEE gap between backward and advanced provinces (municipalities) gradually narrowed, an evidence of the catch-up effect.

The absolute convergence speed can be computed by the convergence formula of the neoclassical economic growth model:

$$
|\beta|=1-e^{-\theta T}
$$

where, $\theta=-\frac{1}{T} \ln (1-|\beta|)$ is the convergence speed; $T$ is the number of years in the sample period.

By formula (5), the absolute convergence speeds of the overall, midstream, and upstream of the YREB were obtained as $4.37 \%, 1.48 \%, 7.55 \%$ and $2.93 \%$, respectively. Hence, there is a difference between different regions of the YREB in the absolute convergence speed of the TFEE: the TFEE converged fastest in the midstream, followed in turn by the upstream and the downstream.

\subsubsection{Results analysis of conditional BCM}

The conditional BCM (4) for the YREB TFEE was also regressed on Stata 12. The regression results are displayed in Table 4. Similarly, to choose between fixed-effects model and random-effects model, the F-statistic was used to test the panel data on the overall, downstream, midstream, and upstream of the YREB.

As shown in Table 4, the F-statistics of the overall, midstream, and upstream of the YREB were respectively $16.33,25.69$ and11.30, and all passed the significance test at $1 \%$. Thus, fixed-effects model should be selected for the panel data on the overall, midstream, and upstream of the YREB. On the contrary, the F-statistics of the downstream was merely 0.07 , and did not pass the significance test. This means random effects model is more suitable for the panel data on the downstream. 
Table 4. Regression results of conditional BCM

\begin{tabular}{|c|c|c|c|c|}
\hline \multirow{2}{*}{$\frac{\text { Variable }}{\operatorname{Ln}(T F P t-1)}$} & \multicolumn{4}{|c|}{ Overall DownstreamMidstreamUpstream } \\
\hline & $-0.5594^{* * *}$ & $\begin{array}{c}-0.4152^{* * *} \\
(-388)\end{array}$ & $\begin{array}{c}-0.7700^{* * *} \\
(-979)\end{array}$ & $\begin{array}{c}-0.4561^{* * *} \\
(-492)\end{array}$ \\
\hline PGDP & $\begin{array}{c}0.0221^{*} \\
(1.58)\end{array}$ & $\begin{array}{r}-0.0011 \\
(-1.01)\end{array}$ & $\begin{array}{c}0.0481^{*} \\
(1.60)\end{array}$ & $\begin{array}{c}0.0245 \\
(0.70)\end{array}$ \\
\hline$T R D$ & $\begin{array}{l}0.0089 \\
(0.49)\end{array}$ & $\begin{array}{c}-0.0043^{* *} \\
(-2.26)\end{array}$ & $\begin{array}{l}0.0510 \\
(0.28)\end{array}$ & $\begin{array}{l}0.0701 \\
(0.82)\end{array}$ \\
\hline$E C S$ & $\begin{array}{c}-0.0052 \\
(-0.15)\end{array}$ & $\begin{array}{c}-0.0029 \\
(-0.53)\end{array}$ & $\begin{array}{c}0.0235 \\
(0.26)\end{array}$ & $\begin{array}{l}0.0505 \\
(0.74)\end{array}$ \\
\hline$E R S$ & $\begin{array}{l}-2.3125^{*} \\
(-189)\end{array}$ & $-0.5610^{* *}$ & $\begin{array}{r}-1.0427 \\
(-037)\end{array}$ & $\begin{array}{c}-3.9024^{* *} \\
(-206)\end{array}$ \\
\hline$U R B$ & $\begin{array}{c}-0.2376^{*} \\
(-1.67)\end{array}$ & $\begin{array}{c}0.0123 \\
(1.16)\end{array}$ & $\begin{array}{c}-0.5888^{*} \\
(-1.64)\end{array}$ & $\begin{array}{c}-0.2414 \\
(-0.63)\end{array}$ \\
\hline $\operatorname{Adj}^{2}$ & 0.4994 & 0.3322 & 0.6401 & 0.4697 \\
\hline$F$-statistic & $16.33^{* * *}$ & 0.07 & $25.69 * *$ & $11.30^{* * *}$ \\
\hline$o b s$ & 198 & 54 & 72 & 72 \\
\hline
\end{tabular}

Note: The bracketed data in are T-statistic
levels of $10 \%, 5 \%$ and $1 \%$, respectively.

As shown in Table 4, the addition of control variables improved the $\operatorname{Adj}^{2}$ values of the overall, midstream, and upstream of the YREB from the levels in the absolute BCM, indicating that the conditional $\mathrm{BCM}$ has better explanatory power than the absolute BCM.

Besides, the $\operatorname{Ln}(T F E E t-1)$ coefficients of the overall, downstream, midstream, and upstream of the YREB were respectively $-0.5594,-0.4152,-0.7700$, and -0.4561 , and all passed the significance test at $1 \%$. This means the YREB TFEE also have significant conditional beta convergence.

By formula (5), the conditional convergence speeds of the overall, midstream, and upstream of the YREB were obtained as $44.55 \%, 2.98 \%, 8.17 \%$ and $3.38 \%$, respectively. The results were much higher than the absolute convergence speeds.

Except ECS, the control variables, including PGDP, TRD, ERS, and URB, exerted certain impacts on the YREB TFEE from different angles.

The PGDP had a significant positive impact on the TFEE convergence in the overall and midstream of the YREB at the level of $10 \%$, an insignificant positive impact on that in the upstream, and an insignificant negative impact on that in the downstream. The results reveal that: the continuous economic growth across the YREB promotes the upgrading and transform of the industrial structure, laying a solid basis for improving the ability to save energy and reduce emissions. Besides, the regional difference in economic level is still obvious in the YREB: the economically developed downstream has largely completed the shift of growth model; the economy in the midstream is picking up speed and going through paradigm shift; the economically underdeveloped upstream is slow in economic transition. In this context, the PGDP exerts different impacts on the TFEE convergence in different regions of the YREB.

The TRD had insignificant positive impacts on the TFEE convergence in the overall, midstream, and upstream, and significant negative impact on that in the downstream at the level of 5\%. The possible reasons are as follows: The YREB downstream has a relatively large volume of import and export. In particular, heavy industrial products occupy a large portion in the export of Jiangsu and Zhejiang. The production of heavy industry consumes lots of energies, aggravating pollutant emissions. Unlike the downstream, the YREB midstream and upstream mainly import and export light industrial products and agricultural products. Both light industry and agriculture have a small energy demand and low pollutant emissions.
The ECS had insignificant impacts on the TFEE convergence in the overall, downstream, midstream, and upstream of the YREB. This is attributable to the following facts: Although coal is still the mostly consumed energy in the YREB, the proportion of coal in the YREB energy structure is on the decline, as China vigorously advocates the green energy strategy. From 2000 to 2017, that proportion dropped by $15 \%$ from $69 \%$ to $54 \%$.

The ERS had negative impacts on the TFEE convergence in the overall, downstream, midstream, and upstream of the YREB. The impacts were significant except in the midstream. The results show that: the ERS, as a double-edged sword, fails to force the YREB enterprises to reduce emissions, but brings about the green paradox [30]. This also reflects that most provincial (municipal) governments in the YREB have not developed desirable economic measures, such as investment on industrial pollution control and pollution charge system. The ERS should be further strengthened. Statistics show that the investment on industrial pollution control only took up $0.05 \%$ in the gross industrial output of the YREB in 2017

The URB had significant negative impacts on the TFEE convergence in the overall and midstream of the YREB at the level of $10 \%$, an insignificant negative impact on that in the upstream, and an insignificant positive impact on that in the downstream. The negative impacts on the overall, midstream, and upstream stem from the following facts: Overall, the urbanization rate of the YREB is growing rapidly, especially in the midstream and upstream. The urbanization will inevitably increase the energy demand. But the energy utilization in the upstream and midstream is extensive. Meanwhile, the downstream is already highly urbanized, and makes intensive use of energy. That is why the URB slightly improves the TFEE convergence in the downstream.

\section{CONCLUSION}

This paper sets up an evaluation index system for the YREB TFEE, and measures the 2000-2017 TFEEs in 11 YREB provinces (municipalities), using the DDF model. Moreover, the TEFF convergence in the YREB and its subregions was examined by the BCM. The main conclusions are as follows:

(1) The YREB provinces (municipalities) differed greatly in TFEE. Among them, Shanghai, Zhejiang, and Yunnan achieved the optimal TFEEs in the sample period; Jiangsu, Anhui, Hubei, Hunan, Chongqing, and Sichuan realized relatively good TFEEs, which could be further improved; Jiangxi and Guizhou did not output desirable TFEEs, leaving ample room for improvement.

(2) There were significant TFEE differences between the upstream, midstream, and downstream. The three regions can be ranked as downstream, midstream, and upstream in descending order of the TFEE. Therefore, midstream, and upstream should be the focus of energy saving and emission reduction in the YREB.

(3) The YREB TFEE exhibited significant absolute beta convergence. The midstream TFEE had the fastest absolute convergence speed, followed in turn by the upstream TFEE and the downstream TFEE. The addition of control variables improved the conditional convergence speeds of YREB TFEEs.

(4) Except ECS, the control variables, including PGDP, TRD, ERS, and URB, exerted major impacts on the YREB TFEE. The impacts varied from region to region. 
Based on the above conclusions, the YREB is advised to further improve the TFEE and narrow the regional TFEE gap from the following aspects:

(1) Following the national strategy of high-quality economic growth, the YREB should transform the traditional growth model of high input, high energy, and high emissions into a new model of low input, low energy, and low emissions.

(2) To further optimize the import and export structure, the YREB should phase out high-energy, high-emission production equipment, promote the green transform of enterprise production, and encourage the development of hightech industries, pushing up the proportion of high-tech products in import and export.

(3) The YREB should further implement the green energy strategy, establish clean energy production bases, and gradually reduce the consumption of fossil energies by harnessing clean energies like hydropower, wind power and bioenergy.

(4) The YREB should step up environmental regulation, and invest more on industrial pollution control. Besides, the pollution charge system should be established, forcing enterprises to save energy and reduce emissions.

(5) The YREB should replace the traditional extensive model of urban development with a new urbanization model, which is intensive, smart, green, and low-carbon. Under the new model, the concept of ecological civilization is fully integrated into the entire urbanization process.

\section{REFERENCES}

[1] Sinton, J.E., Levine, M.D. (1994). Changing energy intensity in Chinese industry: The relatively importance of structural shift and intensity change. Energy Policy, 22(3): 239-255. $\quad$ https://doi.org/10.1016/03014215(94)90162-7

[2] Garbaccio, R.F., Ho, M.S., Jorgenson, D.W. (1999). Why has the energy-output ratio fallen in China. The Energy Journal, 20(3): 63-91.

[3] Honma, S., Hu, J.L. (2008). Total-factor energy efficiency of regions in Japan. Energy Policy, 36(2): 821833. https://doi.org/10.1016/j.enpol.2007.10.026

[4] Byrnes, P., Freeman, M., Kauffman, D. (1997). Performance measurement and financial incentives for community behavioral health services provision. International Journal of Public Administration, 20(8-9): $1555-1578$.

https://doi.org/10.1080/01900699708525263

[5] Conrad, K. (2000). An econometric model of production with endogenous improvement in energy efficiency, 1970-1995. Applied Economics, 32(9): 1153-1160. https://doi.org/10.1080/000368400404290

[6] Seiford, L.M., Zhu, J. (2002). Modeling undesirable factors in efficiency evaluation. European Journal of Operational Research, 142(1): 16-20. https://doi.org/10.1016/S0377-2217(01)00293-4

[7] Färe, R., Grosskopf, S., Pasurka Jr, C.A. (2007). Environmental production functions and environmental directional distance functions. Energy, 32(7): 1055-1066. https://doi.org/10.1016/j.energy.2006.09.005

[8] Boyd, G.A., Pang, J.X. (2000). Estimating the linkage between energy efficiency and productivity. Energy Policy, 28(5): 289-296. https://doi.org/10.1016/S03014215(00)00016-1
[9] Hu, J.L., Kao, C.H. (2007). Efficient energy-saving targets for APEC economies. Energy Policy, 35(1): 373382. https://doi.org/10.1016/j.enpol.2005.11.032

[10] Miao, R., Jin, Y. (2014). The measurement and analysis of regional energy efficiency in China. Journal of Chemical and Pharmaceutical Research, 6(3): 729-734.

[11] Lin, B., Long, H. (2015). A stochastic frontier analysis of energy efficiency of China's chemical industry. Journal of Cleaner Production, 87: 235-244. https://doi.org/10.1016/j.jclepro.2014.08.104

[12] Caro-Martínez, R., Sendra, J.J. (2018). Implementation of urban building energy modeling in historic districts. Seville as case- study. International Journal of Sustainable Development and Planning, 13(4): 528-540. https://doi.org/10.2495/SDP-V13-N4-528-540

[13] Bai, Y., Niu, J., Hao, Y. (2012). Research of regional energy efficiency based on undesirable outputs and its influential factors: a case of western China. Energy Procedia, 16 : 802-809. https://doi.org/10.1016/j.egypro.2012.01.129

[14] Zhang, X.P., Cheng, X.M., Yuan, J.H., Gao, X.J. (2011). Total-factor energy efficiency in developing countries. Energy Policy, 39(2): 644-650. https://doi.org/10.1016/j.enpol.2010.10.037

[15] Wei, C., Ni, J., Shen, M. (2009). Empirical analysis of provincial energy efficiency in China. China \& World Economy, 17(5): 88-103. https://doi.org/10.1111/j.1749124X.2009.01168.X

[16] Fisher-Vanden, K., Jefferson, G.H., Jingkui, M., Jianyi, $X$. (2006). Technology development and energy productivity in China. Energy Economics, 28(5-6): 690705. https://doi.org/10.1016/j.eneco.2006.05.006

[17] Schleich, J. (2004). Do energy audits help reduce barriers to energy efficiency? An empirical analysis for Germany. International Journal of Energy Technology and Policy, 2(3): 226-239. https://doi.org/10.1016/S01968904(02)00051-1

[18] Hepbasli, A., Ozalp, N. (2003). Development of energy efficiency and management implementation in the Turkish industrial sector. Energy Conversion and Management, 44(2): 231-249. https://doi.org/10.1016/j.enpol.2011.10.050

[19] Shahbaz, M., Lean, H.H. (2012). Does financial development increase energy consumption? The role of industrialization and urbanization in Tunisia. Energy Policy, 40(1): 473-479.

[20] Charnes, A., Cooper, W.W., Rhodes, E. (1978). Measuring the efficiency of decision making units. European Journal of Operational Research, 2(6): 429444.

[21] Chambers, R.G., Chung, Y., Färe, R. (1996). Benefit and distance functions. Journal of Economic Theory, 70(2): 407-419. https://doi.org/10.1006/jeth.1996.0096

[22] Barro, R.J., Sala-i-Martin, X., (1991). Convergence across states and regions. Brookings Papers on Economic Activity, 22(1): https://doi.org/10.2307/2534639

[23] Brookes, L. (2000). Energy efficiency fallacies revisited. Energy Policy, 28(6-7): 355-366. https://doi.org/10.1016/S0301-4215(00)00030-6

[24] Murtishaw, S., Schipper, L. (2001). Disaggregated analysis of US energy consumption in the 1990s: Evidence of the effects of the internet and rapid 
economic growth. Energy Policy, 29(15): 1335-1356. https://doi.org/10.1016/S0301-4215(01)00093-3

[25] Herrerias, M.J., Joyeux, R., Girardin, E. (2013). Shortand long-run causality between energy consumption and economic growth: Evidence across regions in China. Applied $\quad$ Energy, 112: 1483-1492. https://doi.org/10.1016/j.apenergy.2013.04.054

[26] Gollop, F.M., Roberts, M.J. (1983). Environmental regulations and productivity growth: The case of fossilfueled electric power generation. Journal of Political Economy, 91(4): 654-674.

[27] Hu, J.L., Wang, S.C. (2006). Total-factor energy efficiency of regions in China. Energy Policy, 34(17): 3206-3217. https://doi.org/10.1016/j.enpol.2005.06.015
[28] Li, L.B., Hu, J.L. (2012). Ecological total-factor energy efficiency of regions in China. Energy Policy, 46: 216224. https://doi.org/10.1016/j.enpol.2012.03.053

[29] Simsek, N. (2014). Energy efficiency with undesirable output at the economy-wide level: Cross country comparison in OECD sample. American Journal of Energy Research, 2(1): 9-17. https://doi.org/10.12691/ajer-2-1-2

[30] Sinn, H.W. (2008). Public policies against global warming: A supply side approach. International Tax and Public Finance, 15(4): 360-394. https://doi.org/10.1007/s10797-008-9082-z 